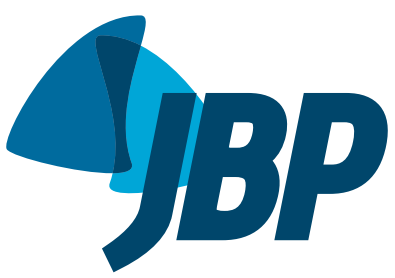

\title{
Respiratory muscles in COPD: be aware of the diaphragm
}

\author{
Pauliane Vieira Santana ${ }^{1, a}$, Andre Luis Pereira de Albuquerque ${ }^{1, b}$
}

COPD is a limiting respiratory disease associated with high morbidity and mortality. ${ }^{(1)}$ COPD is characterized by chronic airflow limitation due to small airway disease and parenchymal destruction. ${ }^{(1)}$ Dyspnea and exercise intolerance (EI) are common in patients with COPD and are associated with reduced quality of life and increased mortality. ${ }^{(2,3)}$ Dyspnea and EI might result from an imbalance in the load/capacity ratio of the respiratory muscles in COPD patients. Chronic airflow limitation imposes a load on respiratory muscles (as does lung hyperinflation), flattening the diaphragm and reducing its ability to generate tension. In patients with COPD, various other factors can impair respiratory muscle function, including activation of proteases, oxidative stress, malnutrition, ageing, and comorbidity-related systemic factors; however, changes in chest wall geometry and diaphragm position are the most commonly recognized and studied mechanisms contributing to respiratory muscle dysfunction. ${ }^{(4)}$

Diaphragm function has been largely evaluated in COPD patients. It has been demonstrated that inspiratory muscle weakness is related to dyspnea. ${ }^{(5-7)}$ In addition to being related to EI and increased dyspnea, respiratory strength has been reported to be related to survival in COPD patients. ${ }^{(3)}$ Therefore, it is relevant that respiratory muscles and diaphragm function in particular be assessed in COPD patients.

In an article published in the current issue of the JBP, Gonçalves et al. ${ }^{(8)}$ showed that COPD patients with thoracic hyperkyphosis ( $\mathrm{TH}$ ) had lower diaphragmatic mobility when compared with a group of patients with COPD and no TH. Furthermore, the authors showed a negative correlation between diaphragmatic mobility and TH: a greater thoracic kyphosis translates to a lower diaphragmatic mobility. The authors hypothesized that a decrease in diaphragmatic mobility results in changes in the body posture in patients with COPD. However, TH might be a consequence of ageing alone and, in fact, impair diaphragmatic mobility.

Regardless of the real cause of TH (COPD or ageing), few studies have explored the impact of postural changes in patients with COPD, although thoracic alterations are commonly observed in clinical practice. Thus, elderly individuals, in whom COPD is more prevalent, can present with severe $\mathrm{TH}$ that can compromise diaphragmatic mobility and ventilatory function, of these patients, as well as contributing to further respiratory impairment in COPD patients.

Taking into account the clinical implications of diaphragmatic mobility, Dos Santos Yamaguti et al. ${ }^{(9)}$ noted that diaphragmatic mobility was lower in COPD patients than in healthy elderly individuals, and that air trapping was related to reduced diaphragmatic mobility. By means of ultrasound study, Paulin et al. ${ }^{(10)}$ showed that patients with COPD and low diaphragmatic mobility presented with increased limitation in exercise capacity and increased post-exertional dyspnea during the six-minute walk test. More recently, using chest X-rays, Rocha et al. ${ }^{(11)}$ noted that, in patients with COPD, diaphragmatic mobility was related to airway obstruction, lung hyperinflation, ventilatory capacity, and perception of dyspnea, but not to physical activity in daily life.

As demonstrated by Gonçalves et al., ${ }^{\left({ }^{8}\right)}$ diaphragmatic dysfunction might be present in COPD patients with $\mathrm{TH}$; however, as demonstrated in the study by Gonçalves et al., $^{\left({ }^{(8)}\right.}$ this topic has yet to be fully elucidated. First, there is question of the clinical relevance of the findings, given that no association was found between reduced diaphragmatic mobility and reduced maximal inspiratory pressure. Perhaps there is a decrease in diaphragmatic strength (transdiaphragmatic pressure) rather than in total inspiratory strength (when accessory inspiratory muscles are acting). Second, the fact that lung volumes, symptoms, and exercise capacity were not evaluated limits the clinical implications of lower mobility. Third, diaphragmatic mobility was assessed by chest X-rays. Although this method is noninvasive and easily performed, it involves the use of ionizing radiation, the transportation of the patient to the radiology sector, and patient cooperation in order to perform diaphragmatic breathing measurements. Diaphragm ultrasound (DUS) has been widely used in order to evaluate diaphragm dysfunction because of its advantages (safety, feasibility, repeatability, and reproducibility). ${ }^{(12,13)}$ In addition, DUS allows the measurement of thickness and thickening of the diaphragm, a surrogate for contractility. ${ }^{(14)}$ Moreover, a recent study has demonstrated that diaphragmatic dysfunction defined by reduced thickening fraction on DUS ( $<20 \%$ ) is related to prognostic implications in acutely exacerbated COPD patients. ${ }^{(15)}$ Lastly, the study by Gonçalves et al. ${ }^{(8)}$ is a descriptive study, and, therefore, it is impossible to evaluate the cause-and-effect relationship between $\mathrm{TH}$ and reduction of diaphragmatic mobility. Table 1 shows the most common variables studied by means of imaging methods for evaluating the diaphragm, as well as their clinical implications in healthy individuals and in patients with respiratory disorders.

Considering the importance and clinical relevance of this topic, although symptoms were not measured in that study ${ }_{1}^{\left({ }^{8}\right)}$ it is clear that TH resulted in lower diaphragmatic mobility in COPD patients and, therefore, has a potential to 
Table 1. The most common variables studied by means of imaging methods for evaluating the diaphragm and their clinical implications in healthy individuals and in patients with respiratory disorders.

\begin{tabular}{|c|c|c|}
\hline Variable & Clinical implication & Method \\
\hline Mobility & $\begin{array}{c}\text { Lung function } \\
\text { Inspiratory muscle strength } \\
\text { Dyspnea } \\
\text { Exercise capacity } \\
\text { Prediction of weaning from MV } \\
\text { Diagnosis of diaphragmatic dysfunction }\end{array}$ & $\begin{array}{c}\text { Chest X-rays } \\
\text { Diaphragm ultrasound }\end{array}$ \\
\hline Thickness & $\begin{array}{c}\text { Inspiratory muscle strength } \\
\text { Diagnosis of diaphragmatic dysfunction } \\
\text { Assessment of progression of atrophy during MV }\end{array}$ & $\begin{array}{c}\text { Diaphragm ultrasound } \\
\text { CT }\end{array}$ \\
\hline Thickening fraction (\%) & $\begin{array}{l}\text { Lung function } \\
\text { Inspiratory muscle strength } \\
\text { Diagnosis of diaphragmatic dysfunction } \\
\text { Assessment of progression of atrophy during MV } \\
\text { Assessment of respiratory effort during MV } \\
\text { Prediction of weaning from MV }\end{array}$ & Diaphragm ultrasound \\
\hline
\end{tabular}

MV: mechanical ventilation.

impair diaphragmatic strength. Future studies exploring the impact of chest wall alterations on diaphragm performance and their clinical implications in COPD patients are of high interest.

\section{REFERENCES}

1. Global Initiative for Chronic Obstructive Lung Disease (GOLD) [homepage on the Internet]. Bethesda: GOLD; c2017 [cited 2017 Feb 10]. GOLD 2017 Global Strategy for the Diagnosis, Management and Prevention of COPD. Available from: http://goldcopd.org/gold-2017global-strategy-diagnosis-management-prevention-copd/

2. Zielinski J, MacNee W, Wedzicha J, Ambrosino N, Braghiroli A Dolensky J, et al. Causes of death in patients with COPD and chronic respiratory failure. Monaldi Arch Chest Dis. 1997;52(1):43-7.

3. Gray-Donald K, Gibbons L, Shapiro SH, Macklem PT, Martin JG Nutritional status and mortality in chronic obstructive pulmonary disease. Am J Respir Crit Care Med. 1996;153(3):961-6. https://doi. org/10.1164/ajrccm.153.3.8630580

4. Orozco-Levi M. Structure and function of the respiratory muscles in patients with COPD: impairment or adaptation? Eur Respir J Suppl. 2003;46:41s-51s. https://doi.org/10.1183/09031936.03.00004607

5. Newell SZ, McKenzie DK, Gandevia SC. Inspiratory and skeletal muscle strength and endurance and diaphragmatic activation in patients with chronic airflow limitation. Thorax. 1989;44(11):903-12 https://doi.org/10.1136/thx.44.11.903

6. Polkey Ml, Kyroussis D, Hamnegard $\mathrm{CH}$, Mills GH, Green M Moxham J. Diaphragm strength in chronic obstructive pulmonary disease. Am J Respir Crit Care Med 1996;154(5):1310-7. https://doi. org/10.1164/ajrccm.154.5.8912741

7. Killian KJ, Jones NL. Respiratory muscles and dyspnea. Clin Chest Med 1988;9(2):237-48

8. Gonçalves MA, Leal BE, Lisboa LG, Tavares MGS, Yamaguti WP Paulin E. Comparison of diaphragmatic mobility between COPD patients with and without thoracic hyperkyphosis: a cross-sectional study. J Bras Pneumol. 2018;44(1):5-11.

9. Dos Santos Yamaguti WP, Paulin E, Shibao S, Chammas MC, Salge
JM, Ribeiro M et al. Air trapping: The major factor limiting diaphragm mobility in chronic obstructive pulmonary disease patients. Respirology. 2008;13(1):138-44. https://doi.org/10.1111/j.14401843.2007.01194.x

10. Paulin E, Yamaguti WP, Chammas MC, Shibao S, Stelmach R, Cukier $A$, et al. Influence of diaphragmatic mobility on exercise tolerance and dyspnea in patients with COPD. Respir Med. 2007;101(10):2113 8. https://doi.org/10.1016/j.rmed.2007.05.024

11. Rocha FR, Brüggemann AK, Francisco DS, Medeiros CS, Rosal D Paulin E. Diaphragmatic mobility: relationship with lung function, respiratory muscle strength, dyspnea, and physical activity in daily life in patients with COPD. J Bras Pneumol. 2017;43(1):32-37. https:// doi.org/10.1590/s1806-37562016000000097

12. Boussuges $A$, Gole $Y$, Blanc $P$. Diaphragmatic motion studied by m-mode ultrasonography: methods, reproducibility, and norma values. Chest. 2009;135(2):391-400. https://doi.org/10.1378/ chest.08-1541

13. Testa A, Soldati G, Giannuzzi R, Berardi S, Portale G, Gentilon Silveri N. Ultrasound M-mode assessment of diaphragmatic kinetics by anterior transverse scanning in healthy subjects. Ultrasound Med Biol. 2011;37(1):44-52. https://doi.org/10.1016/j. ultrasmedbio.2010.10.004

14. Ueki J, De Bruin PF, Pride NB. In vivo assessment of diaphragm contraction by ultrasound in normal subjects. Thorax 1995;50(11):1157-61. https://doi.org/10.1136/thx.50.11.1157

15. Antenora $F$, Fantini $R$, lattoni A, Castaniere I, Sdanganelli A, Livrier $F$, et al. Prevalence and outcomes of diaphragmatic dysfunction assessed by ultrasound technology during acute exacerbation of COPD: A pilot study. Respirology. 2017;22(2):338-344. https://doi org/10.1111/resp.12916 